\title{
Erratum: Hutchinson, Rascher, and Jennings (2016)
}

In the article by Hutchinson, M., Rascher, D.A., and Jennings, K., "A Smaller Window to the University: The Impact of Athletic De-Escalation on Status and Reputation," in Journal of Intercollegiate Sport, 9, 1, http://dx.doi.org/10.1123/ jis.2015-0028, the authors failed to cite Bouchet, Laird, Troilo, Hutchinson, and Ferris (in press) in the original manuscript. Appropriate citations of Bouchet et al. (in press) are now included in this corrected article. The online version of this article has been corrected. 